\title{
Anterior segment optical coherence tomography assessment of corneal thickness before and after primary pterygium surgery
}

Ahmed Hasan Aldghaimy ${ }^{a}$, Ossama AbdEl meneim El_sagheir ${ }^{\text {a }}$, Reham Mostafa Mohamed ${ }^{\text {a* }}$ , Mohamed Ateto Hamed

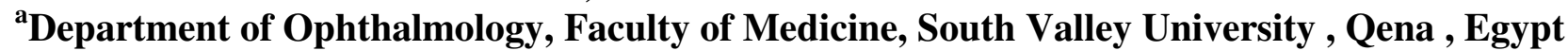

${ }^{b}$ Department of Ophthalmology, Faculty of Medicine, Luxor University , Luxor, Egypt

\begin{abstract}
Background: Anterior Segment Optical Coherence Tomography is the key tool to assess the corneal thickness. Pterygium is one of the most common ocular surface diseases. Our research about evaluation one of the corneal and conjunctival disorders with anterior segment OCT
\end{abstract}

Objectives: Main purpose for our study is to evaluate corneal thickness before and after pterygium excision by anterior segment OCT.

Patient and Methods: This study was performed between September 2020 and April 2021. Cases were recruited from outpatient clinic and inpatient wards of ophthalmology department in Qena University hospital. In each patient one eye was included in the study.

Results: Our study included 40 patients of both sexes and evaluation of corneal thickness revealed that thickness preoperative is $862.2 \pm 93.4 \mu \mathrm{m}$ and one week post operative is $480.1 \pm 57.9 \mu \mathrm{m}$ and one month post operative is $500.4 \pm 56.1 \mu \mathrm{m}$.. Mean of corneal thickness pre-operative /postoperative one week was $382.05 \pm 100.2$ with statically significant relationship with $\mathrm{P}$ value $=0.00$. Mean of corneal thickness pre-operative /postoperative one month was $361.67 \pm 102.6$ with statically significant relationship $\mathrm{P}$ value $=0.00$. Mean of corneal thickness one month post-operative /one week post-operative $20.37 \pm 24$. 5 with statically significant relationship $\mathrm{P}$ value 0.00 .

Conclusion: This study revealed that corneal thickness decreased after pterygium surgery and after one week from surgery the epithelium completely healed to reach average normal thickness which is also affected by aging and some diseases.

Key words: Pterygium, Corneal thickness, Anterior segment Optical Coherence Tomography.

\section{Introduction:}

Pterygium described as a wing-shaped growth of fibrovascular conjunctiva into the cornea. Pterygium is considered as growth disorder of conjunctivalisation of cornea as the localized ultra violet promotes destruction to the limbal stem cells. (Walsh et al., 2011)

Pterygium is one of the Tendon's capsule and bulbar conjunctiva commonest ocular disorders; it known as fibrovascular over growth conjunctiva over corneal surface. Incidence of pterygium is about $0.7 \%$ to $31 \%$. (Huang et al., 2018)
Pathogenesis of this disorder is not completely understood. Age; hereditary elements, sun rays, chronic inflammation, trauma and heat are probable elements (Igarashi et al., 219) .

Fourier domain OCT although it can measure values from center of cornea to the periphery and also it could evaluate posterior surface curvature of cornea (Elhamaky et al., 2018). Images by anterior segment OCT used to evaluate size of pterygium, after imaging, program was used to evaluate horizontal pterygium length and also corneal pterygium

Copyright: () Aldghaimy et al. (2022) Immediate open access to its content on the principle that making research freely available to the public supports a greater global exchange of knowledge. 
size (Wang et al., 2019).

In the anterior segment of the eye; corneal and epithelial thickness can be measured by OCT. (Kuo et al., 2019). OCT Scheimpflug topographer imaging system was reported to accurately determine different corneal properties as curvature and topography system was reported to accurately determine different corneal properties as curvature and topography of anterior and posterior corneal surfaces and also its thickness (Anguria et al., 2014). Anterior segment OCT is used mostly for evaluation thickness of cornea. (Kheirkhah et al., 2011). We aimed to evaluate corneal thickness before and after pterygium excision by anterior segment OCT.

\section{Patients and methods}

\section{a. Inclusion criteria}

Adult patient above 35 years old of primary and recurrent pterygium. Clinical diagnosis based on slit lamp examination.

\section{b. Exclusion criteria}

Children and uncooperative patients with disturbed conscious level and patients with significant ocular surface diseases.

\section{Study methods}

All patients were subjected to the following:

1. Full medical history including detailed systemic and ophthalmologic history (age, sex, diabetes Mellitus \& collagen disease).

\section{Visual acuity:}

a) Uncorrected visual acuity

b) Best corrected visual acuity

c) Refraction: autorefractometer (Topcon RM 8000 B. Topcon Corporation of Tokyo, Japan).

2. Intra ocular pressure by Goldman applanation tonometer.
3. Slit lamp examination of the anterior segment to examine eyelids.

4. Anterior segment optical coherence topography. \{(Heidelberg engineering GmbH) 69121 Heidelberg/Germany SN:TR-KT-2069 Manufactured: $02 / 13$ \} for evaluation of corneal thickness at head of pterygium before pterygium surgery then one week and one month post-operative.

Surgical technique: operation done by one surgeon. Dissection body of pterygium to $4 \mathrm{~mm}$ from limbus, till bare sclera. Using of crescent knife for scrapping any corneal remnants.

Conjunctival thickened parts and adjacent Tenon's capsule with tortuous vessels were excised. Hemostasis occur simultaneously and no need for cautery. Finally we cover the operated eye with bandage for one day.

Follow up: patients were informed about visits for follow-up.

\section{Statistical Analysis}

-Sample size was 40 eyes. Data was collected and analyzed those using SPSS (Statistical Package for the Social Science, version20 and NewYork).

-Expression of continuous data in form of mean $\pm \mathrm{S} D$ or median (range) however expression of nominal data in form of frequency (percentage).

-Comparing the nominal data of groups using $\mathrm{Chi}^{2}$-test however comparing mean of different two groups by using student t-test.

- Determination of the diagnostic performance for corneal thickness at head of pterygium by anterior segment OCT device using ROC curve. 
- Determination of the correlation between corneal thickness at head of pterygium before and after pterygium surgery using Pearson correlation.

- $\mathrm{P}$ value was considered significant if $<0.05$.

- P value was considered highly significant if $<0.001$.

\section{Results}

Male to female ratio was $26 / 14$, right affected eye represent $47.5 \%$ of cases and left eye represent $52 \%$ of cases .

Patients who don't have collagen disease represent $92.5 \%$ of cases \& 2 cases have rheumatoid arthritis \& one case has lupus disease $.57 .5 \%$ of cases don't have D.M. \& the others have D.M. (Table 1) .

Mean age of the cases was $64.5 \pm 11.5$ years.

Mean corneal thickness pre-operative was $862.2 \pm 93.4 \mu \mathrm{m}$.

Mean corneal thickness post-operative one week was $480.1 \pm 57.9 \mu \mathrm{m}$.

Mean corneal thickness post-operative one month was $500.4 \pm 56.1 \mu \mathrm{m}$ (Table 2) .

There is statically significant relation between thickness of cornea preoperative $\&$ post-operative one week.

There is statically significant relation between thickness of cornea preoperative \& postoperative one month.

There is statically significant relation between thickness of cornea postoperative one month $\&$ postoperative one week. (Table 3) .

There was no statically significance relationship regarding sex or affected eye in relation to reaching average normal corneal thickness.

While there was statically significance relationship regarding age $\&$ reaching average normal corneal thickness. (Table 4) .

Regarding to D.M. :100\% of cases who don't have D.M. reaching the average normal corneal thickness while $57.1 \%$ of those who have D.M. don't reach average normal corneal thickness \& $52.9 \%$ of cases who have D.M. have delayed reaching average normal corneal thickness with statically significance relationship.

All cases who have rheumatoid arthritis \& lupus don't reach average normal corneal thickness after one month with statically significance relationship.(Table 5) .

Mean age of cases who don't reach the average normal corneal thickness was 72.3 while those have delayed reaching normal corneal thickness was 56 while those reaching average normal corneal thickness was 23.6 (Fig.1).

Table 1. Quantitative data of the studied groups

\begin{tabular}{|l|c|c|}
\hline \multicolumn{2}{|l|}{ Variables } & No(\%) \\
\hline gender & male & $26(65 \%)$ \\
\cline { 2 - 3 } Affected eye & female & $14(35 \%)$ \\
\cline { 2 - 3 } & right & $19(47.5 \%)$ \\
\hline \multirow{2}{*}{$\begin{array}{l}\text { Collagn } \\
\text { disease }\end{array}$} & left & $21(52.5 \%)$ \\
\cline { 2 - 3 } & $\begin{array}{c}\text { no } \\
\text { rheumatoid }\end{array}$ & $37(92.5 \%)$ \\
\hline \multirow{2}{*}{ Diabetes } & lupus & $1(2.5 \%)$ \\
\hline \multirow{2}{*}{ mellitus } & no & $23(57.5 \%)$ \\
\cline { 2 - 3 } & yes & $17(42.5 \%)$ \\
\hline
\end{tabular}

Table 2. Comparison of the corneal thickness according to the time of operation:

\begin{tabular}{|l|c|}
\hline \multicolumn{1}{|c|}{ Variables } & \multicolumn{1}{|c|}{$\begin{array}{c}\text { Mean } \pm \\
\text { standered } \\
\text { deviation }\end{array}$} \\
\hline Age & $64.5 \pm 11.5 \mathrm{ys}$ \\
\hline $\begin{array}{l}\text { Corneal thickness } \\
\text { Preoperative }\end{array}$ & $862.2 \pm 93.4 \mu \mathrm{m}$ \\
\hline $\begin{array}{l}\text { Corneal thickness post- } \\
\text { operative 1 week }\end{array}$ & $480.1 \pm 57.9 \mu \mathrm{m}$ \\
\hline $\begin{array}{l}\text { Corneal thickness post- } \\
\text { operative 1 month }\end{array}$ & $500.4 \pm 56.1 \mu \mathrm{m}$ \\
\hline
\end{tabular}


Table 3. Comparison of the corneal thickness according to the time of operation:

\begin{tabular}{|l|c|c|c|}
\hline \multicolumn{1}{|c|}{ variables } & $\begin{array}{c}\text { Mean } \pm \\
\text { standered } \\
\text { deviation }\end{array}$ & t & $\begin{array}{c}\text { P } \\
\text { value }\end{array}$ \\
\hline $\begin{array}{l}\text { corneal thickness } \\
\text { preoperative - } \\
\text { post operative 1 } \\
\text { week }\end{array}$ & $382.05 \pm 100.2$ & 24.1 & $0.000 *$ \\
\hline $\begin{array}{l}\text { corneal thickness } \\
\text { preoperative - } \\
\text { post operative 1 } \\
\text { month }\end{array}$ & $361.67 \pm 102.6$ & 22.2 & $0.000 *$ \\
\hline $\begin{array}{l}\text { corneal thickness } \\
\text { post-operative 1 } \\
\text { month - post } \\
\text { operative 1 week }\end{array}$ & $20.37 \pm 24.5$ & 5.16 & $0.000 *$ \\
\hline
\end{tabular}

Table 4. comparison of the base line information of the studied groups regarding reaching the average normal corneal thickness:

\begin{tabular}{|c|c|c|c|c|c|}
\hline \multirow{2}{*}{\multicolumn{2}{|c|}{ variable }} & \multicolumn{3}{|c|}{$\begin{array}{c}\text { Reaching the average normal } \\
\text { corneal thickness }\end{array}$} & \multirow[t]{2}{*}{$\begin{array}{c}\mathbf{P} \\
\text { Value }\end{array}$} \\
\hline & & $\begin{array}{l}\text { Delayed } \\
\mathrm{N}=17\end{array}$ & Yes $N=16$ & No $N=7$ & \\
\hline \multirow{2}{*}{$\operatorname{sex}$} & Male & $11(64.7 \%)$ & $6(37.5 \%)$ & $4(57.1 \%)$ & \multirow{2}{*}{0.23} \\
\hline & Femal & e6(35.3\%) & $10(62.5 \%)$ & $3(42.9 \%)$ & \\
\hline \multicolumn{2}{|c|}{ Age (ys) } & $56 \pm 7.4$ & $23.6 \pm 3.04$ & $\begin{array}{l}72.3 \pm \\
9.5\end{array}$ & $0.000 * *$ \\
\hline \multirow{2}{*}{$\begin{array}{c}\text { Affec } \\
\text { ted } \\
\text { eye }\end{array}$} & Right & $11(64.7 \%)$ & $8(50 \%)$ & 0 & \multirow[b]{2}{*}{0.3} \\
\hline & Left & $6(35.3 \%)$ & $8(50 \%)$ & $7(100 \%)$ & \\
\hline
\end{tabular}

Table 5. comparison of the clinical state of the studied groups regarding reaching the average normal corneal thickness:

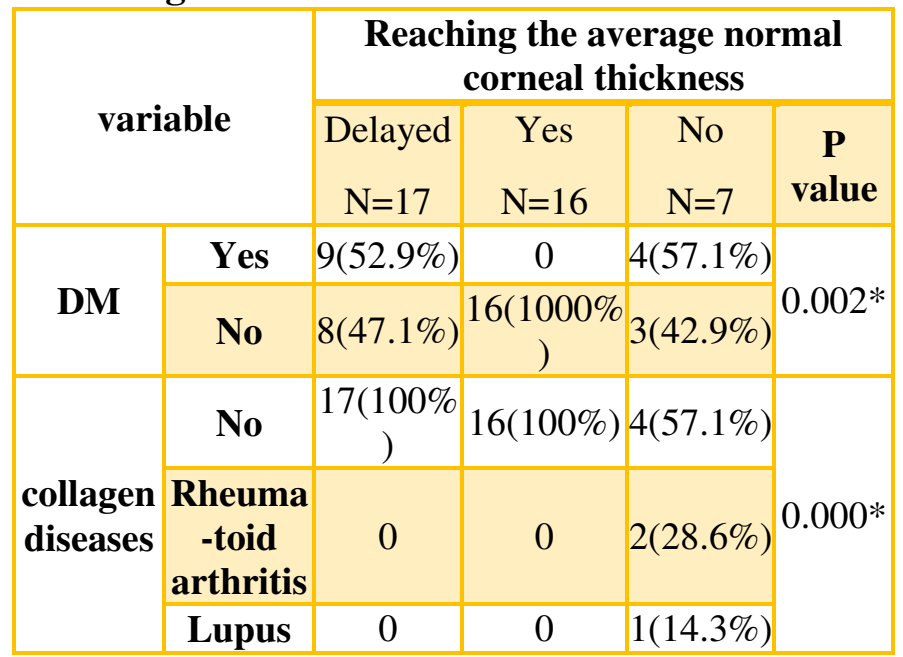

There was no statically significant relationship regarding sex or affected eye in relation to reaching average normal corneal thickness .while there was statically significant relationship regarding age \& reaching average normal thickness with $\mathrm{P}$ value 0.00

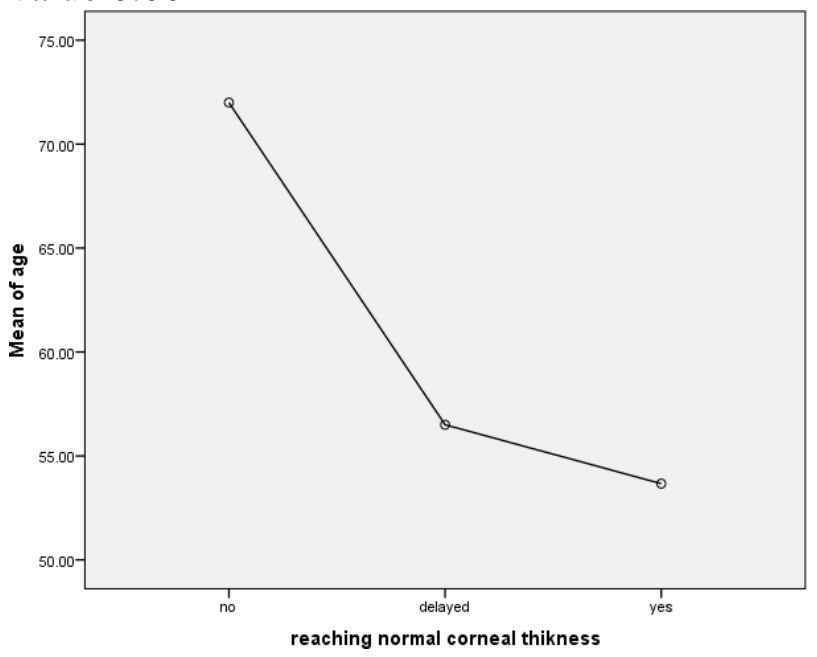

Fig.1. Mean age of the studied regarding Reaching the average normal corneal thickness.

Clinical cases

Case (1): Patient with primary pterygium alone

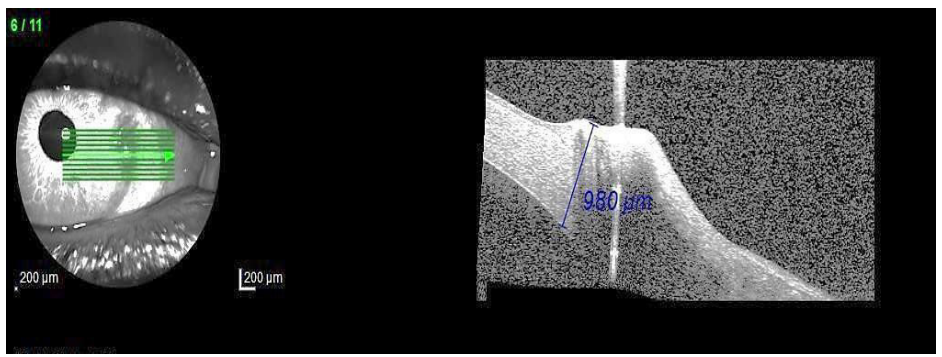

Fig.2. Pre operative.

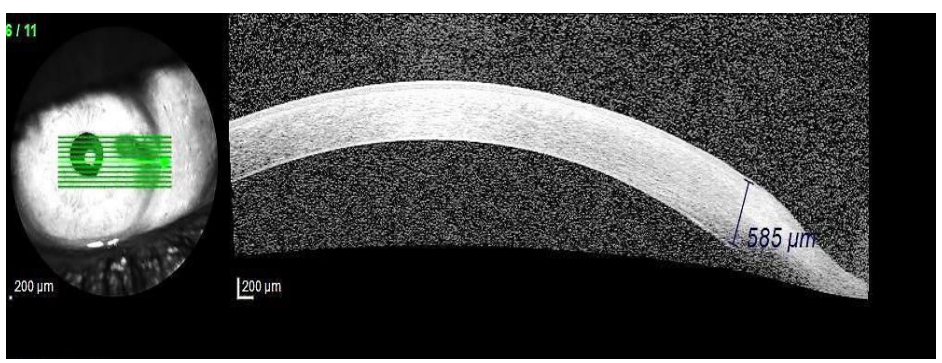

Fig.3. One week post operative.

Case (2): (Primary pterygium patient with diabietis mellitus ) 


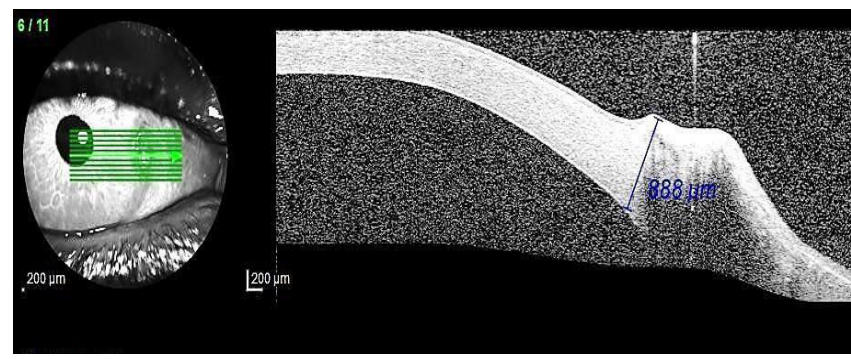

Fig.4. Preoperative .

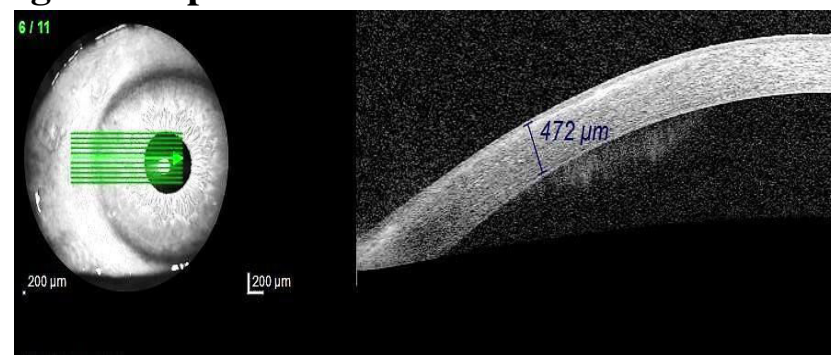

Fig. 5. One week post operative

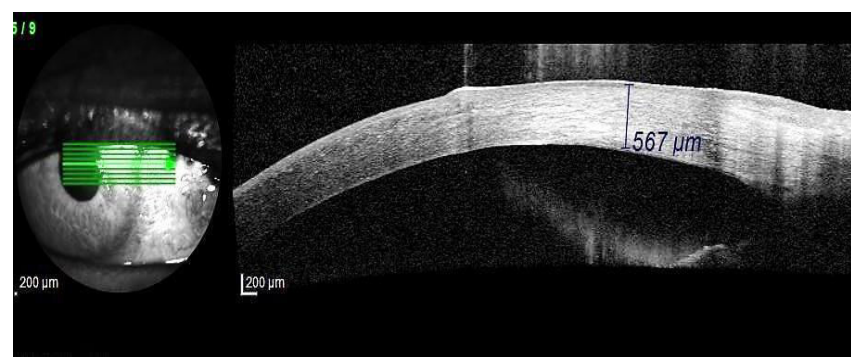

Fig.6. One month post operative

Case (3): (Primary pterygium patient with rheumatoid artheritis)

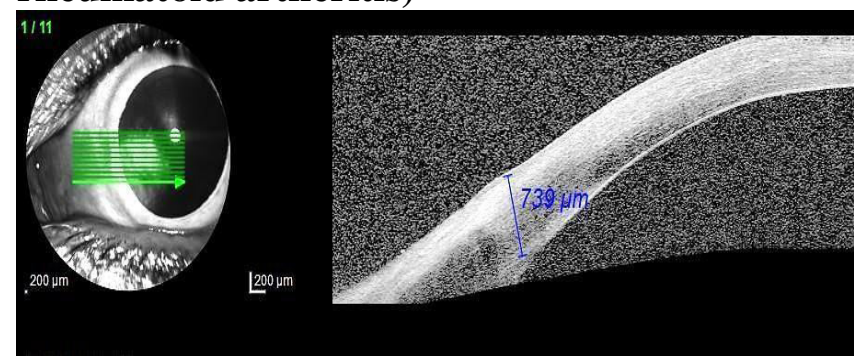

Fig. 7. Preoperative

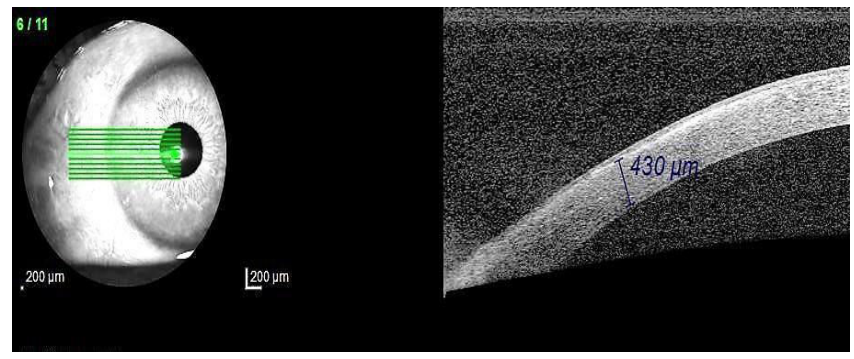

Fig. 8. One week post operative

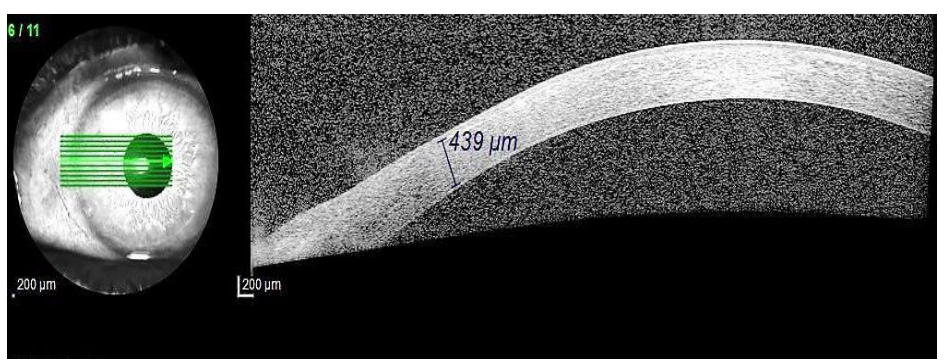

Fig. 9. One month post operative

\section{Discussion}

This study evaluates the corneal thickness before and after pterygium surgery and observed that Surgical excision remains the main treatment for pterygium causing impaired vision, cosmetic deformity, restriction of ocular motility, and/or marked irritation unrelieved by medical management (Clearfield et al., 2016). This suggests that evaluation of pterygium thickness is considered as high quality cross- sectional images and could be done via AS-OCT. (Altan et al., 2013).

Using anterior segment OCT images of cornea and pterygium would help in understanding more about the anatomical characters of corneal tissues and pterygium mass (Maldonado et al., 2010). Our study included 40 patients completed the whole study. Among the studied patients 16 (40\%) reach the average normal corneal thickness after one week, 17 (42\%) delayed healing of epithelial layer of corneal thickness and 7 $(17 \%)$ have no healing of epithelial layer even after one month and though they didn't reach the average normal corneal thickness.

Peripheral corneal thinning with aging is informed in the present researches. 
Thinning of the peripheral cornea in generally normal adults could be important in assessment of subjects for refractive surgery (Jonuscheit et al., 2017).

Systemic lupus patients have statistically significant thinner central corneal pachymetry and also lower thinnest pachymetry comparing to normal subjects. That significance decreased after evaluation of sex like females have corneal thickness more thinner (Eissaet al., 2020). Previous studies approved that central corneal thickness and the Peripheral corneal thickness were significantly thinner in RA patients than controlled subjects. The mean corneal volume was also significantly lower in the RA group than in controlled subjects. (Anayol et al., 2017) Improvement in the condition of epithelial scaffold and also corneal epithelial stimulation require complete epithelial wound closure in some diabetic patients (Lindquistet al., 2015).

\section{Conclusion}

This study revealed that corneal thickness decreased after pterygium surgery which has statically significant difference (0.002) and after one week from surgery the epithelium healed to reach average normal corneal thickness. And it also revealed that it is affected by aging and some diseases such as diabietes mellitus and collagen disease (rheumatoid arthritis, systemic lupus erythromatous) in diabetic patients and old age there was delayed healing in epithelial layer of cornea after pterygium excision surgery result in decrease corneal thickness and it will completely heal after one month. But in collagen disease there was no healing of epithelial layer of cornea even after one month which decreases below average normal corneal thickness and this would affect the visual acuity as it would increases the astigmatism.

\section{References}

- Altan-Yaycioglu R, Kucukerdonmez C, Karalezli A, Corak F , Akova Y A. (2013). Astigmatic changes following pterygium removal: comparison of 5 different methods. Indian journal of ophthalmology, 61(3): 104.

- Anayol M A, Bostancı B, Şekeroğlu M A, Şimşek M, Günaydın $S$ and Yılmazbaş P. (2017). Assessment of corneal densitometry in rheumatoid arthritis patients. Turkish journal of ophthalmology, 47(3): 125.

\section{- Anguria P, Kitinya J, Ntuli S,} Carmichael T. (2014). The role of heredity in pterygium development. International journal of ophthalmology, 7(3): 563.

- Clearfield E, Muthappan V, Wang X, Kuo I. C. (2016). Conjunctival autograft for pterygium. Cochrane Database of Systematic Reviews, (2).

- Eissa I M, Nassar GA, Arfeen S A, Dahab A A. (2020). Evaluation of 
Central and Peripheral Corneal Thicknesses in Patients with Systemic Lupus Erythematosus. Clinical Ophthalmology (Auckland, NZ), 14: 589.

- Huang X, Zhu B, Lin L, Jin X. (2018). Clinical results for combination of fibrin glue and nasal margin suture fixation for attaching conjunctival autografts after pterygium excision in Chinese pterygium patients. Medicine, 97:(44).

- Igarashi N, Honjo M, Fujishiro T, Toyono T, Ono T, Mori Y, Aihara M. (2019). Activation of the Sphingosine 1 Phosphate-Rho Pathway in Pterygium and in Ultraviolet-Irradiated Normal Conjunctiva. International journal of molecular sciences, 20(19): 4670.

- Jonuscheit S, Doughty M J, Martín R, Rio-Cristobal A. (2017). Relationship between corneal thickness and radius to body height. Optometry and Vision Science; 94(3): 380-386.

- Kheirkhah A, Adelpour M, Nikdel M, Ghaffari R, Ghassemi H, Hashemi H. (2011). Evaluation of conjunctival graft thickness after pterygium surgery by anterior segment OCT . Current eye research, 36(9): 782-786.

- Kuo AN, McNabb RP, Izatt J A.
(2019). Advances in whole-eye optical coherence tomography imaging. The Asia-Pacific Journal of Ophthalmology, 8(2): 99-104.

- Lindquist T P, Lee W B. (2015). Mitomycin $\mathrm{C}$-associated scleral stromalysis after pterygium surgery. Cornea, 34(4): 398-401.

- Maldonado R S, Izatt J A, Sarin N, Wallace D K, Freedman S, Cotten CM, Toth C A. (2010). Optimizing hand-held spectral domain optical coherence tomography imaging for neonates, infants, and children. Investigative ophthalmology $\&$ visual science, 51(5):2678-2685.

- Elhamaky T R, Elbarky A M. (2018). Outcomes of vertical split conjunctival autograft using fibrin glue in treatment of primary doubleheaded pterygia. Journal of ophthalmology, 22(9): 18-30.

- Walsh J.E ,Bergmanson and J. P. (2011). Does the eye benefit from wearing ultraviolet-blocking contact lenses?. Eye \& contact lens, 37(4): 267-272.

- Wang S. B, Cornish E E, Grigg J R, McCluskey P J. (2019). Anterior segment optical coherence tomography and its clinical applications. Clinical and Experimental Optometry, 102(3): 195-207. 